\title{
Inhibition of heat shock protein 90 attenuates post-angioplasty intimal hyperplasia
}

\author{
MOHAMMED M. KASSEM ${ }^{1,2}$, FURQAN MUQRI ${ }^{1,2}$, MARY DACOSTA $^{3}$, \\ DAVID BRUCH $^{1,2}$, VIVIAN GAHTAN ${ }^{1,2}$ and KRISTOPHER G. MAIER ${ }^{1,2}$
}

${ }^{1}$ Department of Surgery, Division of Vascular Surgery and Endovascular Services, SUNY Upstate Medical University;
${ }^{2}$ Department of Veterans Affairs VA Healthcare Network Upstate New York at Syracuse;
${ }^{3}$ College of Medicine, MD Program, SUNY Upstate Medical University, Syracuse, NY 13210, USA

Received April 9, 2019; Accepted July 1, 2019

DOI: $10.3892 / \mathrm{mmr} .2020 .10994$

\begin{abstract}
Intimal hyperplasia (IH) is a pathologic process that leads to restenosis after treatment for peripheral arterial disease. Heat shock protein 90 (HSP90) is a molecular chaperone that regulates protein maturation. Activation of HSP90 results in increased cell migration and proliferation. 17-N-allylamino-17-demethoxygeldanamycin (17-AAG) and 17-dimethylaminoethylamino-17-demethoxygeldanamycin (17-DMAG) are low toxicity Food and Drug Association approved HSP90 inhibitors. The current study hypothesized that HSP90 inhibition was predicted to reduce vascular smooth muscle cell (VSMC) migration and proliferation. In addition, localized HSP90 inhibition may inhibit post-angioplasty IH formation. For proliferation, VSMCs were treated with serum-free media (SFM), 17-DMAG or 17-AAG. The selected proliferative agents were SFM, platelet derived growth factor (PDGF) or fibronectin. After three days, proliferation was measured. For migration, VSMCs were treated with SFM, 17-AAG or 17-DMAG with SFM, PDGF or fibronectin as chemoattractants. Balloon injury to the carotid artery was performed in rats. The groups included in the present study were the control, saline control, $17-\mathrm{DMAG}$ in $20 \%$ pluronic gel delivered topically to the adventitia or intraluminal delivery of 17-DMAG. After 14 days, arteries were fixed and sectioned for morphometric analysis. Data was analyzed using ANOVA or a student's t-test. $\mathrm{P}<0.05$ was considered to indicate a statistically significant difference. The results revealed that $17-\mathrm{AAG}$ and 17-DMAG had no effect on cell viability. PDGF and fibronectin also increased VSMC proliferation and migration.
\end{abstract}

Correspondence to: Dr Kristopher G. Maier, Department of Surgery, Division of Vascular Surgery and Endovascular Services, SUNY Upstate Medical University, 750 East Adams Street, Syracuse, NY 13210, USA

E-mail: maierkg@gmail.com

Key words: heat shock protein 90, intimal hyperplasia, pluronic gel, balloon arterial injury, 17-N-allylamino-17-demethoxygeldanamycin, 17-dimethylaminoethylamino-17-demethoxygeldanamycin
Furthermore, both 17-AAG and 17-DMAG decreased cell migration and proliferation in all agonists. Topical adventitial treatment with 17-DMAG after balloon arterial injury reduced IH. HSP90 inhibitors suppressed VSMC proliferation and migration without affecting cell viability. Topical treatment with a HSP90 inhibitor (DMAG) decreased IH formation after arterial injury. It was concluded that 17-DMAG may be utilized as an effective therapy to prevent restenosis after revascularization.

\section{Introduction}

Peripheral arterial disease (PAD) remains a major clinical problem that can lead to disability, limb loss and is potentially fatal in the elderly $(1,2)$. Growth factors and extracellular matrix proteins are important mediators in the pathogenesis of PAD and the development of restenosis secondary to intimal hyperplasia (IH) after balloon angioplasty $(3,4)$. IH is a complex process that begins by platelet activation $(5,6)$. Platelets then bind to the area of vascular injury releasing many agents including thrombospondin-1 (TSP-1) and platelet derived growth factor (PDGF) (5), which in turn cause vascular smooth muscle (VSMC) migration into the area of injury where they begin to proliferate and produce extracellular matrix (5). All of these processes clearly contribute to IH by regulating the arterial response to injury. Recently heat shock protein 90 (HSP90) has also been implicated in pathologic vascular remodeling (7).

HSP90 is a molecular chaperone that binds many signaling proteins regulating their final maturation (8). HSP90 is ubiquitously expressed and is important for normal cell function (8). However, aberrant activation of HSP90 can result in increased cell migration and proliferation (8). Inhibition of HSP90 has been examined in states of aberrant cell growth such as cancer (8). Several different HSPs have been detected in atherosclerosis, and HSP90, in particular, is strongly expressed in atherosclerotic plaque (9). However, the role HSP90 plays in IH after balloon angioplasty is unknown. At least one previous study has shown that blocking HSP90 inhibits VSMC proliferation and migration (9). As the development of IH depends on VSMC migration and proliferation, inhibition of HSP90 may be an efficacious approach to this 
important clinical problem. The quintessential HSP90 inhibitor is the natural product geldanamycin; however, geldanamycin exhibits a relatively high toxicity $(10,11)$. Several derivatives of geldanamycin have been created that have significantly less toxicity and are in clinical trials for cancer therapy, two of these are 17-N-allylamino-17-demethoxygeldanamycin (17-AAG) and 17-dimethylaminoethylamino-17-demethoxygeldanamycin (17-DMAG) $(10,12)$.

In the present study, we sought to understand the contribution of HSP90 in VSMC physiologic processes and IH formation after arterial balloon injury. We hypothesized that HSP90 inhibition would reduce agonist-induced VSMC proliferation and migration, and that localized HSP90 inhibition would inhibit post-angioplasty IH formation.

\section{Materials and methods}

Materials. Smooth muscle cell growth and basal medium were purchased from Cell Applications, Inc. (San Diego, CA). Trypsin and trypsin neutralizing solution were purchased from Cell Applications Inc. (San Diego, CA). 17-AAG and 17-DMAG were purchased from Tocris Bioscience (Bristol, UK). Fibronectin and PDGF were purchased from R\&D Systems (Minneapolis, MN).

Cell culture. Human aortic VSMCs (Cell Applications, Inc., San Diego, CA, USA) were used in early passage (P3-P5). Cells were made quiescent by incubation in serum free media (SFM) for $48 \mathrm{~h}$ at $37^{\circ} \mathrm{C}$ in a tissue culture incubator $\left(5 \% \mathrm{CO}_{2}\right)$.

Cell viability. Cell viability was determined with the Trypan Blue exclusion assay (Thermo Fisher Scientific, Waltham, MA) using the Countess Cell counter (Thermo Fisher Scientific, Waltham, MA) according to the manufacturer's instructions. All experiments were performed in triplicate studying 17-AAG or 17-DMAG at three different concentrations (100 nM, 10 or $30 \mu \mathrm{M})$. The doses chosen have been previously shown to be effective (13).

Migration assay. Chemotaxis was assessed in quiescent human VSMCs incubated in a 96-well FluoroBlok migration plate (One Riverfront Plaza, Corning, NY) according to the manufacturer's instructions with 50,000 calcein AM labeled cells per well. Experiments were performed in triplicate. Cells were exposed to the chemoattractant agents: SFM (negative control), PDGF $20 \mathrm{ng} / \mathrm{ml}$ (positive control) or Fibronectin $20 \mu \mathrm{g} / \mathrm{ml}$ (positive control), which were placed in the bottom chamber. VSMCs treated with $17-\mathrm{AAG}(100 \mathrm{nM}, 10$ or $30 \mu \mathrm{M})$ or $17-\mathrm{DMAG}$ $(100 \mathrm{nM}, 10 \mu \mathrm{M}$ or $30 \mu \mathrm{M})$ for $2 \mathrm{~h}$ at $37^{\circ} \mathrm{C}$ in a tissue culture incubator $\left(5 \% \mathrm{CO}_{2}\right)$ in addition to SFM (negative control) and PDGF or fibronectin (positive control) were placed in the top chamber. Migrated cells were measured on a fluorescent plate reader with excitation of $480 \mathrm{~nm}$ and emission of $520 \mathrm{~nm}$. Data is expressed as relative fluorescence units (RFU).

Proliferation assay. Cell proliferation was assessed in growth-arrested VSMCs incubated in a 96 well plate with 5,000 cells/well. Experiments were performed in triplicate. Quiescent cells were exposed to serum free media (SFM), PDGF (20 ng/ml) or Fibronectin (20 $\mu \mathrm{g} / \mathrm{ml}), 17-A A G(100 \mathrm{nM}$,
10 or $30 \mu \mathrm{M})$ or 17-DMAG (100 nM, 10 or $30 \mu \mathrm{M})$. VSMCs were incubated for $72 \mathrm{~h}$ at $37^{\circ} \mathrm{C}$ in a tissue culture incubator $\left(5 \% \mathrm{CO}_{2}\right)$. Proliferation was measured using a MTS tetrazolium absorbance assay (Cell Titer 96 Aqueous Cell Proliferation Assay, Promega, Madison, WI) according to manufacturer's instructions.

Carotid artery balloon injury model. This study was approved by the Syracuse VA IACUC and the animal care complied with the Guide for the Care and Use of Laboratory Animals. Sprague-Dawley rats at 10-12 weeks of age (Harlan Laboratories, Indianapolis, IN) were randomized into four groups (8-10 animals per group)-control, saline control, intraluminal 17-DMAG or topical 17-DMAG. 17-DMAG was selected as the HSP90 inhibitor for the in vivo work because of ease of use (water soluble) and equivalent lack of toxicity to cells and inhibition of VSMC proliferation in vitro. Rats were anesthetized using inhaled isoflurane at 5\% and then maintained at $2 \%$ for the surgery. The left common carotid artery (CCA) and its bifurcation were exposed via carotid artery cutdown. A 2F Fogarty catheter (Edwards Lifesciences, Irvine, CA) was placed into the CCA via the external carotid artery and the balloon was inflated (5 atmospheres for $5 \mathrm{~min}$ ). Then a polyethylene (PE) catheter attached to a pump was placed into the vessel and the vessel gently distended with either saline $(0.9 \%, \mathrm{PH}=8.5)$ with flow rate $10 \mathrm{ml} / \mathrm{min}$ in saline control and topical treatment groups or 17-DMAG $(500 \mathrm{nM})$ suspended in saline for $20 \mathrm{~min}$ (intraluminal treatment group). The catheter was withdrawn, and the external carotid artery ligated. For the topical group, 17-DMAG (500 nM) in 20\% pluronic gel (F-127, Anaspec, Fermont, CA) was placed on top of the vessel prior to closing the incision. We chose 17-DMAG for the in vivo part of the study over 17-AAG as it is more water soluble and has better bioavailability than 17-AAG (12) Thereby, delivery formulations of 17-DMAG do not require organic solubilizing agents which have their own limitations. After 14 days, the animals were euthanized and bilateral CCAs were perfusion fixed, harvested, sectioned, stained with hematoxylin and eosin and morphometric analysis was performed to assess severity of IH. Two groups have been assigned as control groups for this particular study, isolated angioplasty injury (control) and angioplasty plus intraluminal saline infusion (saline control). The reason behind using dual control groups is to exclude the assumption of concomitant saline injury to the vessel wall.

Morphometric analysis. The left CCA was fixed in paraffin, sectioned, stained with hematoxylin and eosin for crosssectional morphometric analysis. The medial thickness (M) was quantified between the internal (IEL) and external elastic (EEL) laminae, i.e., M=EEL-IEL. The intimal thickness (I) was measured between the endothelial cell layer and the internal elastic lamina, i.e., I=IEL-Luminal area. The ratio of intimal area to medial area was calculated as the intimal thickness divided by the combined intimal and medial thickness (14).

Statistical analysis. Data are presented as the mean \pm standard error of the mean. Data was tested via ANOVA with post-hoc testing with Fisher's PLSD in StatView (SAS Institute, Cary, NC) or a Student's t-test. $\mathrm{P}<0.05$ was considered to indicate a statistically significant difference. 


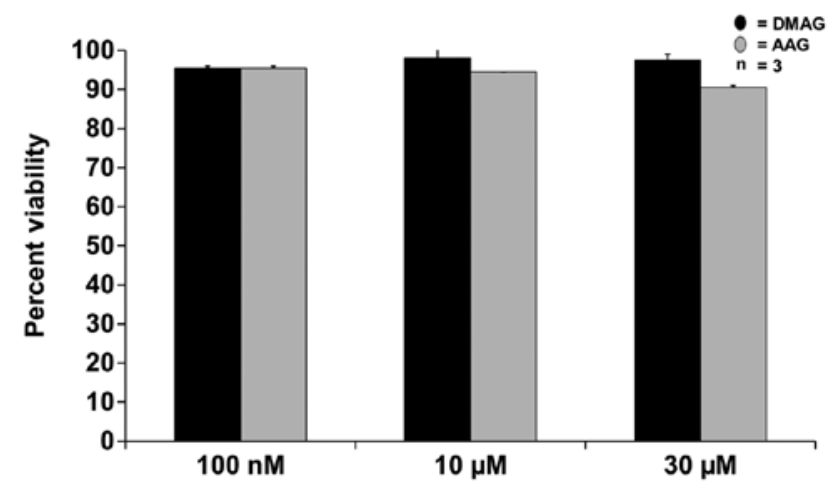

Figure 1. 17-AAG and 17-DMAG exert no toxic effects on VSMCs. VSMCs were treated with different concentrations of 17-AAG or 17-DMAG for $24 \mathrm{~h}$. Viability was assessed using a trypan blue exclusion assay. All groups had a cell viability $>90 \%$. Data are presented as the mean \pm SEM $(n=2) .17-A A G$, 17-N-allylamino-17-demethoxygeldanamycin; 17-DMAG, 17-dimethylaminoethylamino-17-demethoxygeldanamycin; VSMC, vascular smooth muscle cell

\section{Results}

Cell viability. 17-AAG and 17-DMAG had no effect on VSMC viability. After 24-hour incubation, VSMC viable cell count did not significantly change in all tested concentrations $(100 \mathrm{nM}$, $10 \mu \mathrm{M}$ or $30 \mu \mathrm{M}$ ) of either drug. At $100 \mathrm{nM}$, the cells were $95.5 \%$ viable with both 17-AAG and 17-DMAG treatment. At $10 \mu \mathrm{M}$ the viability was $94.5 \%$ for $17-\mathrm{AAG}$ and $98 \%$ for $17-\mathrm{DMAG}$. At the highest tested dose-30 $\mu \mathrm{M}$-cell viability was determined to be $90.5 \%$ for $17-A A G$ and $97.5 \%$ for $17-D M A G$ (Fig. 1).

Migration. 17-AAG and 17-DMAG decreased VSMC migration in response to PDGF. PDGF at a concentration of $20 \mathrm{ng} / \mathrm{ml}$ increased smooth muscle migration by $30 \%$ compared to SFM $(\mathrm{P}=0.0001)$. At the concentration of $100 \mathrm{nM}, 17-\mathrm{AAG}$ decreased migration by $16 \%(\mathrm{P}=0.0048)$ while 17-DMAG decreased migration by $34.9 \%(\mathrm{P}=0.0003)$. Ten $\mu \mathrm{M}$ 17-AAG and 17-DMAG decreased migration by $21.1 \%$ $(\mathrm{P}=0.003)$ and $29.9 \%(\mathrm{P}=0.0002)$ respectively. At $30 \mu \mathrm{M}$, 17-AAG and 17-DMAG were found to decrease migration by $30.8 \%(\mathrm{P}=0.0003)$ and $39.4 \%(\mathrm{P}=0.0003)$ respectively. There was no difference in inhibition of VSMC migration between 17-AAG and 17-DMAG (Fig. 2).

17-AAG and 17-DMAG decreased VSMC migration in response to Fibronectin. Fibronectin at a concentration of $20 \mu \mathrm{g} / \mathrm{ml}$ increased smooth muscle cell migration by $16 \%$ compared to SFM (P=0.01). At a concentration of $100 \mathrm{nM}$, 17-AAG decreased migration by $19.21 \%(\mathrm{P}=0.015)$ while 17-DMAG decreased migration by $13.78 \%(\mathrm{P}=0.03)$. Ten $\mu \mathrm{M}$ 17-AAG and 17-DMAG decreased smooth muscle migration by $15.35(\mathrm{P}=0.01)$ and $21.3 \%(\mathrm{P}=0.01)$ respectively. At $30 \mu \mathrm{M}$, 17-AAG and 17-DMAG were found to decrease migration by $17.3(\mathrm{P}=0.004)$ and $19.2 \%(\mathrm{P}=0.01)$ respectively. There was no difference in inhibition of VSMC migration between 17-AAG and 17-DMAG (Fig. 3).

Proliferation. 17-AAG and 17-DMAG decreased VSMC proliferation in response to PDGF. PDGF at a concentration of $20 \mathrm{ng} / \mathrm{ml}$ increased smooth muscle cell proliferation by $15.42 \%$ compared to $\mathrm{SFM}(\mathrm{P}=0.006)$. At a concentration of $100 \mathrm{nM}$,

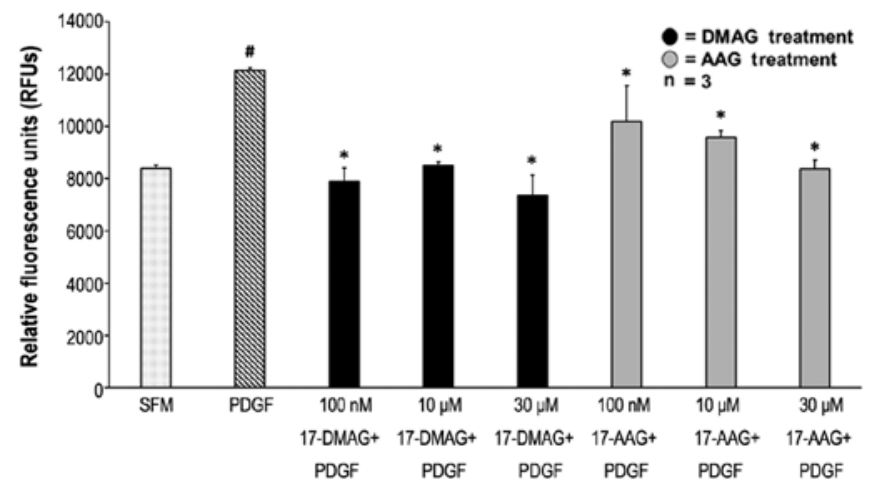

Figure 2. 17-AAG and 17-DMAG decreased VSMC migration to PDGF. VSMCs were treated with different concentrations of either 17-AAG or 17-DMAG in the presence of $20 \mathrm{ng} / \mathrm{ml}$ PDGF as a chemoattractant agent. SFM treatment was used as a negative control. Results were assessed after 120 min. ${ }^{*} \mathrm{P}<0.05$ vs. PDGF; ${ }^{*} \mathrm{P}<0.05$ vs. SFM. Data are presented as the mean \pm SEM $(n=3)$. 17-AAG, 17-N-allylamino-17-demethoxygeldanamycin; 17-DMAG, 17-dimethylaminoethylamino-17-demethoxygeldanamycin; VSMC, vascular smooth muscle cell; platelet derived growth factor; SFM, serum-free media.

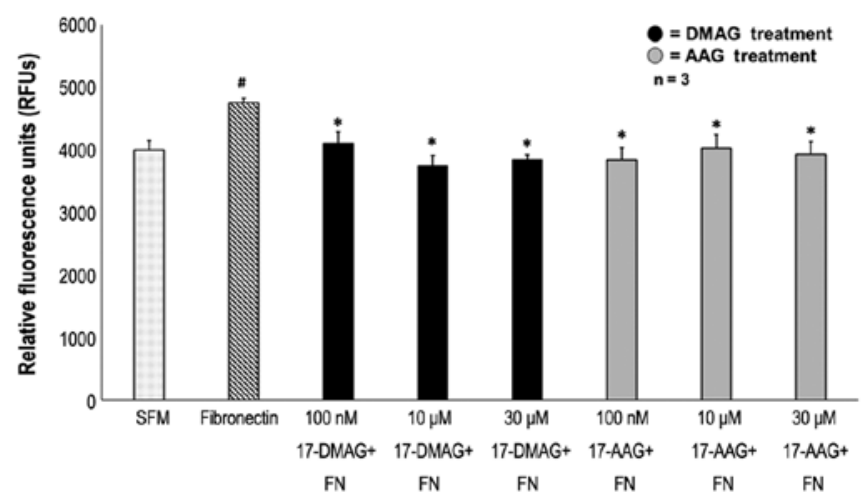

Figure 3. 17-AAG and 17-DMAG decreased VSMC migration to fibronectin. VSMCs were treated with different concentrations of 17-AAG or 17-DMAG in the presence of $20 \mu \mathrm{g} / \mathrm{ml} \mathrm{FN}$ as a chemoattractant. SFM treatment was used as a negative control. Results were assessed after 3 h. ${ }^{*} \mathrm{P}<0.05$ vs. FN; ${ }^{\#} \mathrm{P}<0.05$ vs. SFM. Data are presented as the mean \pm SEM $(n=3) .17-A A G$, 17-N-allylamino-17-demethoxygeldanamycin; 17-DMAG, 17-dimethylaminoethylamino-17-demethoxygeldanamycin; VSMC, vascular smooth muscle cell; FN, fibronectin; SFM, serum-free media.

17-AAG decreased proliferation by $73.9 \%(\mathrm{P}=0.001)$ while 17-DMAG decreased proliferation by $77.5 \%(\mathrm{P}=0.0002)$. Ten $\mu \mathrm{M}$ 17-AAG and 17-DMAG decreased proliferation by $62.6 \%$ $(\mathrm{P}=0.01)$ and $72.8 \%(\mathrm{P}=0.0002)$ respectively. At $30 \mu \mathrm{M}$, 17-AAG and 17-DMAG were found to decrease proliferation by $72.8 \%(\mathrm{P}=0.0002)$ and $72.4 \%(\mathrm{P}=0.0006)$ respectively. There was no difference in VSMC proliferation between 17-AAG and 17-DMAG by PDGF (Fig. 4).

17-AAG and 17-DMAG decreased VSMC proliferation in response to Fibronectin. Fibronectin at a concentration of $20 \mu \mathrm{g} / \mathrm{ml}$ increased smooth muscle proliferation by $25 \%$ absorbance at $490 \mathrm{~nm}$ from 0.18 to $0.24(\mathrm{P}<0.0001)$. At a concentration of $100 \mathrm{nM}, 17-\mathrm{AAG}$ decreased proliferation by $62.9 \%$ (decreased absorbance to $0.089, \mathrm{P}=0.0001$ ) while 17-DMAG decreased proliferation by $67.5 \%$ (decreased absorbance to $0.078, \mathrm{P}=0.0001$ ). At $10 \mu \mathrm{M} 17-\mathrm{AAG}$ and 17-DMAG decreased proliferation by $58.1 \%(\mathrm{P}=0.0001)$ and $55.6 \%$ 


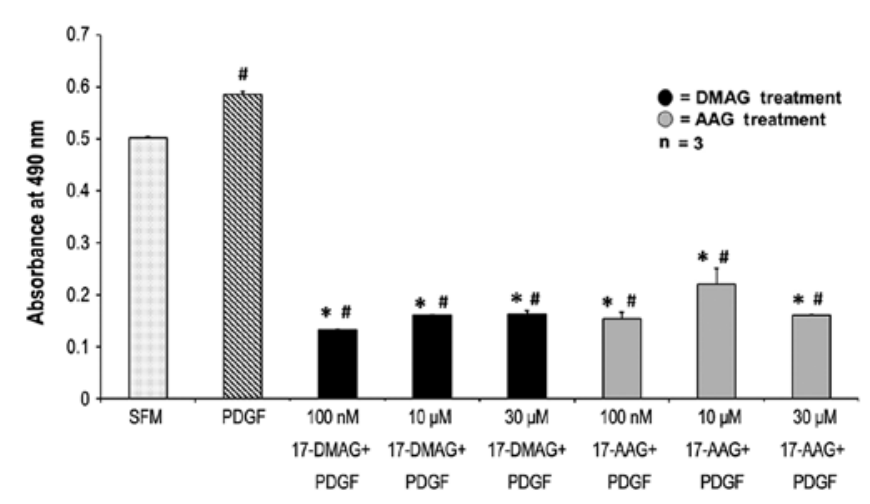

Figure 4. 17-AAG and 17-DMAG decreased VSMC proliferation to PDGF. VSMCs were treated with different concentrations of either 17-AAG or 17-DMAG in the presence of $20 \mathrm{ng} / \mathrm{ml}$ PDGF as a proliferative agent. SFM treatment was used as a negative control. Results were assessed after $72 \mathrm{~h}$. ${ }^{*} \mathrm{P}<0.05$ vs. PDGF; ${ }^{\#} \mathrm{P}<0.05$ vs. SFM. Data are presented as the mean $\pm \mathrm{SEM}$ $(\mathrm{n}=3)$. 17-AAG, 17-N-allylamino-17-demethoxygeldanamycin; 17-DMAG, 17-dimethylaminoethylamino-17-demethoxygeldanamycin; VSMC, vascular smooth muscle cell; PDGF, platelet derived growth factor; SFM, serum-free media.

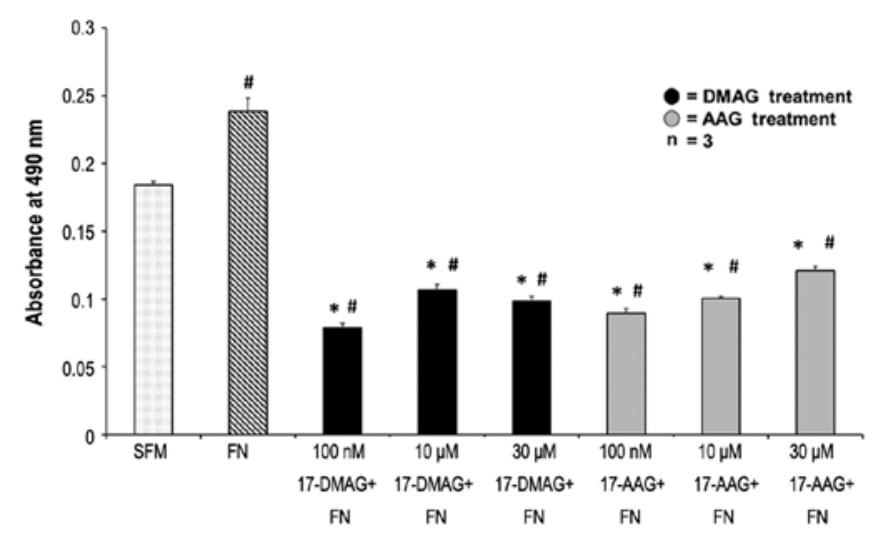

Figure 5. 17-AAG and 17-DMAG decreased VSMC proliferation to fibronectin. VSMCs were treated with different concentrations of 17-AAG or 17-DMAG in the presence of $20 \mu \mathrm{g} / \mathrm{ml} \mathrm{FN}$ as a proliferative agent. SFM treatment was used as a negative control. Results were assessed after $72 \mathrm{~h}$ ${ }^{*} \mathrm{P}<0.05$ vs. FN; ${ }^{\#} \mathrm{P}<0.05$ vs. SFM. Data are presented as the mean \pm SEM $(\mathrm{n}=3)$. 17-AAG, 17-N-allylamino-17-demethoxygeldanamycin; 17-DMAG, 17-dimethylaminoethylamino-17-demethoxygeldanamycin; VSMC, vascular smooth muscle cell; FN, fibronectin; SFM, serum-free media.

( $\mathrm{P}=0.0001)$ respectively. At $30 \mu \mathrm{M}, 17-\mathrm{AAG}$ and 17-DMAG were found to decrease proliferation by $49.6 \%(\mathrm{P}=0.0001)$ and $59 \%(\mathrm{P}=0.0001)$ respectively. There was no difference in the degree of inhibition of VSMC proliferation between 17-AAG and 17-DMAG (Fig. 5).

\section{Morphometric analysis}

Topical 17-DMAG reduces IH after arterial injury in Sprague-Dawley rats. Rats that were treated with adventitial 17-DMAG dissolved in 20\% pluronic gel had $46.5 \%$ less IH when compared to the saline control group $(0.22 \pm 0.02$ vs. $0.42 \pm 0.05, \mathrm{P}=0.001)$. Intra-luminal delivery of 17 -DMAG had no effect on $\mathrm{IH}$, with the control group I/M ratio being $0.41 \pm 0.22$ and the intra-luminal group being $0.38 \pm 0.05$. No difference was determined between control and saline control IH (Figs. 6 and 7).

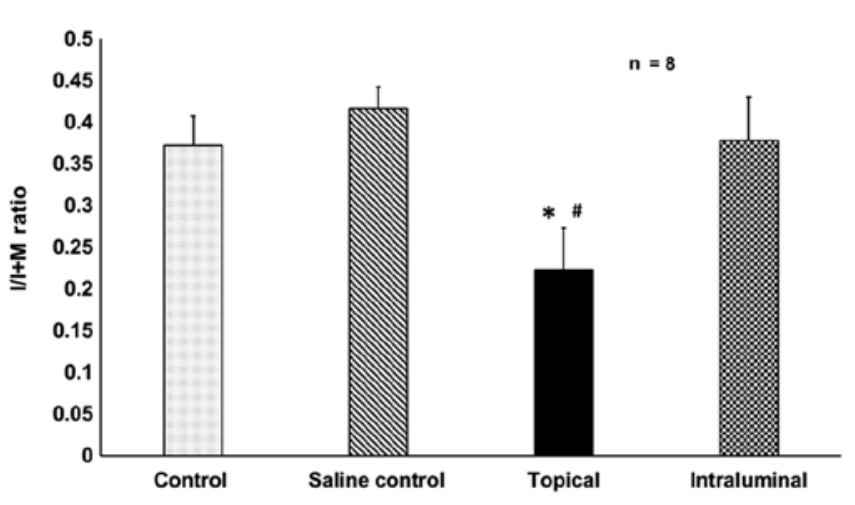

Figure 6. Topical HSP90 inhibition attenuates IH. Topical 17-DMAG treatment attenuated IH and decreased the I/M ratio compared with the untreated group. ${ }^{*} \mathrm{P}<0.05$ vs. the untreated group; ${ }^{\#} \mathrm{P}<0.05$ vs. the saline control. Data are presented as the mean \pm SEM $(n=7)$. HSP90, heat shock protein 90; $I H$, intimal hyperplasia; 7-DMAG, 17-dimethylaminoethylamino-17-demethoxygeldanamycin.

\section{Discussion}

IH is a major cause of long-term failure after either open or endovascular revascularization (15). Despite all the technological advances in endovascular revascularization modalities, restenosis remains a significant risk, particularly within the first 12 months after angioplasty (16). A fuller understanding of the cellular processes behind VSMC migration and proliferation (key processes in IH development), is critical to developing new therapies to attenuate restenosis. The present study examined the role of HSP90 in IH after balloon arterial injury and the potential therapeutic role of HSP90 inhibitors, 17-AAG and 17-DMAG, in attenuating or even preventing IH. Our results demonstrate that 17-DMAG dissolved in $20 \%$ pluronic gel, applied topically on the adventitia of the common carotid artery of Sprague-Dawley rats reduced the amount of IH after injury. We further found that intra-luminal delivery of 17-DMAG dissolved in saline to the injured artery didn't attenuate the IH in the affected animals.

HSPs are a family of conserved intracellular proteins that are involved in proper protein folding which helps both in protein function and intracellular targeting (17). HSP90 is a common member of the HSP family that was found to be overexpressed in atherosclerotic plaque in patients and is associated with plaque instability (18). The essential function of HSP90 is believed to be the interaction with proteins known as clients (19). Many of the clients are protein kinases and transcription factors that regulate cell differentiation, proliferation and apoptosis $(20,21)$.

Proliferation of VSMCs is crucial in the pathogenesis of IH and restenosis $(9,22,23)$. After arterial injury, VSMCs, originating primarily from the adventitia, migrate into the area of vascular injury and proliferate, thus initiating the process of IH. HSP90 has been shown to be involved in the proliferation of many cell types including VSMCs $(21,24-26)$. The current study demonstrates that HSP90 does play a broad role in VSMC proliferation, as 17-AAG and 17-DMAG were able to inhibit VSMC proliferation in response to two functionally different agonists, PDGF and fibronectin.

Geldanamycin, was the first HSP90 inhibitor to be developed; however, this inhibitor has poor solubility and is highly toxic to various human cell types (27). Two main geldanamycin 


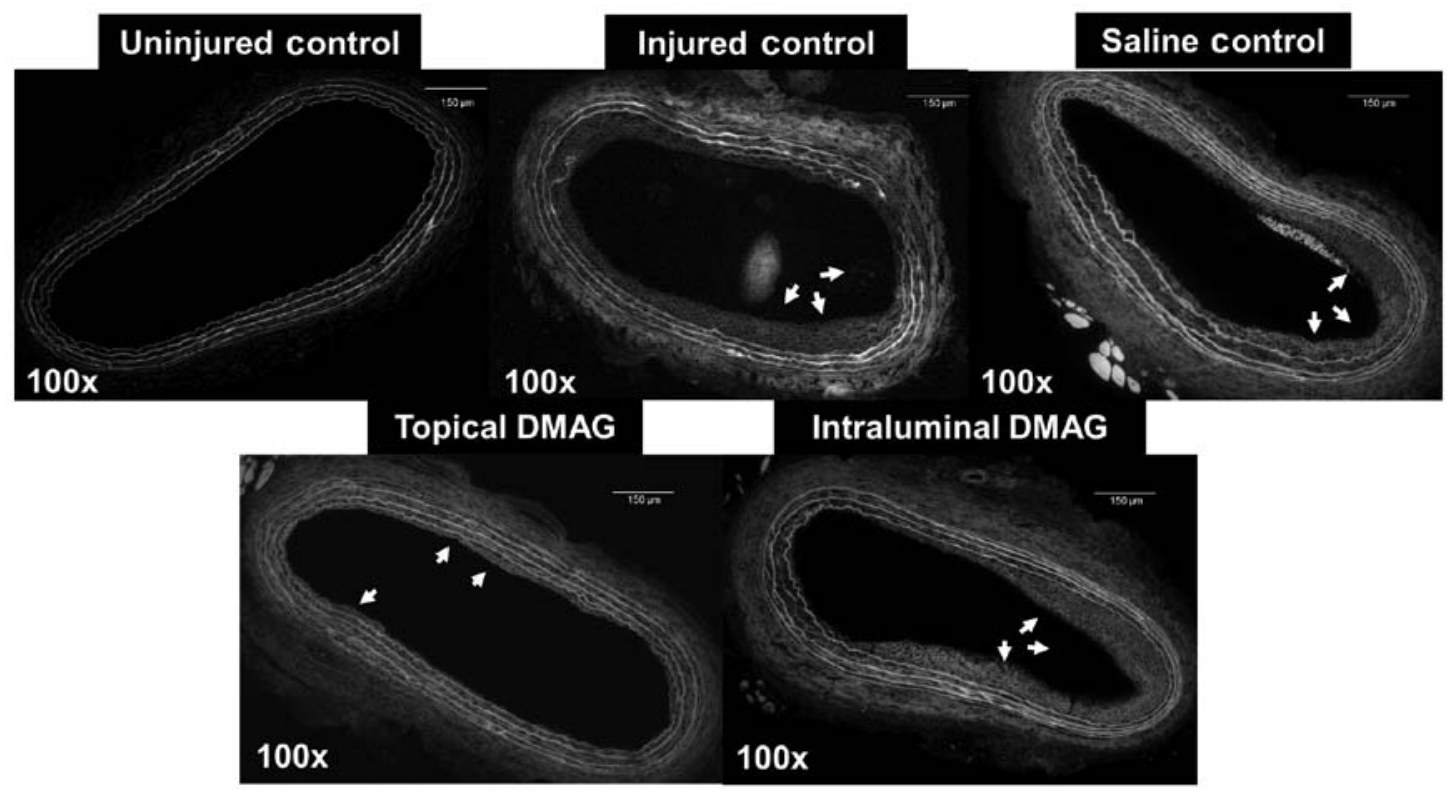

Figure 7. Representative CCA cross sections. The images present representative cross sections of the CCA, obtained via endogenous fluorescence of the blood vessels in an un-injured control, injured control, saline control, topical 17-DMAG and intraluminal 17-DMAG. Scale bar=150 $\mu \mathrm{M}$. CCA, common carotid artery; 7-DMAG, 17-dimethylaminoethylamino-17-demethoxygeldanamycin.

derivatives-17-AAG and 17-DMAG-have less toxicity and have been tested in phase II/III clinical trials as novel antineoplastic agents (9). In the present study, we needed to determine if either geldanamycin derivative has the same cellular toxic effects as geldanamycin $(11,27,28)$. Our data shows that VSMC viability was determined to be above $90 \%$ at any tested concentration of 17-AAG or 17-DMAG used. Both 17-AAG and 17-DMAG work by inhibiting the binding of ATP to HSP90, which is necessary for HSP90 function (18).

The current study further investigated whether HSP90 contributes to the development of IH after arterial injury in an animal model. At least one other study has demonstrated the HSP90 inhibition can attenuate IH (7). However in that study the authors used a peptide inhibitor which can be immunogenic in humans, our study used FDA approved HSP90 inhibitors that have been shown to be safe in humans $(7,12,29)$. Given that our in vitro data demonstrated no differences in efficacy between 17-AAG and 17-DMAG, we chose to use 17-DMAG in vivo as this drug is more water soluble and therefore easier to use. We found topical (periadventitial) delivery of 17-DMAG significantly reduced the formation of $\mathrm{IH}$. The specific downstream effects of HSP90 that account for its role in IH development are unknown. Recent studies showed that HSP90 inhibition downregulates cyclinD3, PCNA, and pRb, leading to cell cycle arrest which could contribute to the antiproliferative effect of either 17-DMAG or 17-AAG (27). These effects and their role in IH will need further study. Our findings indicate that HSP90 is a vital factor in the process of post-arterial injury, including VSMC migration, proliferation and IH.

The present study does have limitations that will need further study. Since HSP90 inhibition affects several intracellular proteins, kinases and intracellular signaling pathways at the same time, other pathophysiological processes such as apoptosis, angiogenesis or oxidative stress could also be affected by the drug used in the study and warrants further investigation to accurately clarify the role of HSP90 in human arterial disease. Another limitation of our study is how to optimize the delivery route of the HSP90 inhibitor agent, as in our model only the periadventitial topical route was found to significantly decrease IH. This method may have been effective because of the longer residence time of the inhibitor with the vessel. Periadventitial delivery is relevant for open revascularization, but may not be practical for endovascular procedures, mitigating a need for further technological advancements to optimize the intraluminal 17-DMAG delivery method. The method used for intraluminal delivery in the current study may have been inadequate for absorbance by the vessel wall. Nanotechnology for the improved delivery of 17-DMAG could be one option. Endovascular adventitial delivery with an infusion device through the arterial wall (e.g., Bullfrog Micro-Infusion Device, Mercator MedSystems) would be an alternative method to endovascular delivery.

In conclusion, the present study demonstrates the significance of HSP90 in the development of IH. In addition, these studies showed no toxic effects of either 17-AAG or 17-DMAG on VSMC viability, indicating possible safety of these agents if used as anti-intimal hyperplastic agents in revascularization procedures. Interestingly, both agents were able to markedly reduce PDGF-induced and fibronectin-induced VSMC migration and proliferation. Topical periadventitial delivery of the HSP90 inhibitor was found to attenuate post-balloon injury IH. The current study provides a foundation for future explorations into potential therapeutic targets for reducing the damaging effects of IH.

\section{Acknowledgements}

The abstract was presented at the 32nd Eastern Vascular Society annual meeting Sep. 6-Sep 82018 in Washington, D.C. and published as abstract no. 3734 in J Vasc Surg 68 e20: 2018 . 


\section{Funding}

The present study was supported by a grant obtained from the United States Department of Defense (grant no. PR 152338).

\section{Availability of data and materials}

The datasets used and/or analyzed during the current study are available from the corresponding author on reasonable request.

\section{Authors' contributions}

MMK performed the experiments, analyzed the data and prepared the manuscript for submission in this work. FM and MD performed the experiments and analyzed data. DB performed all surgical procedures. VG assisted in experimental design, data interpretation and manuscript editing. KGM was the principal investigator of the grant, who designed the present study, interpreted the data, and wrote and edited the manuscript.

\section{Ethics approval and consent to participate}

All animal studies in this manuscript were approved by The Syracuse Department of Veterans Affairs Institutional Animal Care and Use Committee in accordance with AAALAC guidelines.

\section{Patient consent for publication}

Not applicable

\section{Competing interests}

The authors declare that they have no competing interests.

\section{References}

1. Valentine RJ, Grayburn PA, Eichhorn EJ, Myers SI and Clagett GP: Coronary artery disease is highly prevalent among patients with premature peripheral vascular disease. J Vasc Surg 19: 668-674, 1994.

2. McDivitt JD, Braun M and Kassop D: Cardiovascular disease: Lower extremity peripheral artery disease. FP Essent 479: 11-15, 2019.

3. Asakura Y, Suzuki M, Nonogi H, Haze K, Sato A, Inada H, Okuda Y, Yamashita K and Harano Y: Restenosis after percutaneous transluminal coronary angioplasty in patients with non-insulin-dependent diabetes mellitus (NIDDM). J Cardiovasc Risk 5: 331-334, 1998.

4. Goel SA, Guo LW, Liu B and Kent KC: Mechanisms of post-intervention arterial remodelling. Cardiovasc Res 96: 363-371, 2012.

5. Weintraub WS: The pathophysiology and burden of restenosis. Am J Cardiol 100: 3K-9K, 2007

6. Broos K, Feys HB, De Meyer SF, Vanhoorelbeke K and Deckmyn H: Platelets at work in primary hemostasis. Blood Rev 25: 155-167, 2011.

7. Hoel AW, Yu P, Nguyen KP, Sui X, Plescia J, Altieri DC and Conte MS: Mitochondrial heat shock protein- 90 modulates vascular smooth muscle cell survival and the vascular injury response in vivo. Am J Pathol 181: 1151-1157, 2012.

8. Lianos GD, Alexiou GA, Mangano A, Mangano A, Rausei S, Boni L, Dionigi $\mathrm{G}$ and Roukos DH: The role of heat shock proteins in cancer. Cancer Lett 360: 114-118, 2015.

9. Kim J, Jang SW, Park E, Oh M, Park S and Ko J: The role of heat shock protein 90 in migration and proliferation of vascular smooth muscle cells in the development of atherosclerosis. J Mol Cell Cardiol 72: 157-167, 2014.
10. Lang SA, Klein D, Moser C, Gaumann A, Glockzin G, Dahlke MH, Dietmaier W, Bolder U, Schlitt HJ, Geissler EK and Stoeltzing O: Inhibition of heat shock protein 90 impairs epidermal growth factor-mediated signaling in gastric cancer cells and reduces tumor growth and vascularization in vivo. Mol Cancer Ther 6: 1123-1132, 2007.

11. Hermane J, Eichner S, Mancuso L, Schröder B, Sasse F, Zeilinger C and Kirschning A: New geldanamycin derivatives with anti Hsp properties by mutasynthesis. Org Biomol Chem 17: 5269-5278, 2019.

12. Mellatyar H, Talaei S, Pilehvar-Soltanahmadi Y, Barzegar A, Akbarzadeh A, Shahabi A, Barekati-Mowahed M and Zarghami N: Targeted cancer therapy through 17-DMAG as an Hsp90 inhibitor: Overview and current state of the art. Biomed Pharmacother 102: 608-617, 2018

13. Sausville EA, Tomaszewski JE and Ivy P: Clinical development of 17-allylamino, 17-demethoxygeldanamycin. Curr Cancer Drug Targets 3: 377-383, 2003 .

14. Jiang D, Zhuang J, Peng W, Lu Y, Liu H, Zhao Q, Chi C, Li X, Zhu G, Xu X, et al: Phospholipase C $\gamma 1$ mediates intima formation through Akt-Notch1 signaling independent of the phospholipase activity. J Am Heart Assoc 6, 2017.

15. Collins TC, Beyth RJ, Nelson DB, Petersen NJ, SuarezAlmazor ME, Bush RL, Hirsch AT and Ashton CM: Process of care and outcomes in patients with peripheral arterial disease. J Gen Intern Med 22: 942-948, 2007.

16. Schillinger $M$ and Minar E: Restenosis after percutaneous angioplasty: The role of vascular inflammation. Vasc Health Risk Manag 1: 73-78, 2005.

17. Xu Q, Metzler B, Jahangiri M and Mandal K: Molecular chaperones and heat shock proteins in atherosclerosis. Am J Physiol Heart Circ Physiol 302: H506-H514, 2012.

18. Madrigal-Matute J, López-Franco O, Blanco-Colio LM, Muñoz-García B, Ramos-Mozo P, Ortega L, Egido J and Martín-Ventura JL: Heat shock protein 90 inhibitors attenuate inflammatory responses in atherosclerosis. Cardiovasc Res 86: 330-337, 2010.

19. Mayer MP: Gymnastics of molecular chaperones. Mol Cell 39: 321-331, 2010.

20. Pearl LH and Prodromou C: Structure and mechanism of the Hsp90 molecular chaperone machinery. Annu Rev Biochem 75: 271-294, 2006.

21. Mjahed H, Girodon F, Fontenay M and Garrido C: Heat shock proteins in hematopoietic malignancies. Exp Cell Res 318: 1946-1958, 2012.

22. Helkin A, Maier KG and Gahtan V: Thrombospondin-1, -2 and -5 have differential effects on vascular smooth muscle cell physiology. Biochem Biophys Res Commun 464: 1022-1027, 2015.

23. Doran AC, Meller N and McNamara CA: Role of smooth muscle cells in the initiation and early progression of atherosclerosis. Arterioscler Thromb Vasc Biol 28: 812-819, 2008.

24. Liu DH, Yuan HY, Cao CY, Gao ZP, Zhu BY, Huang HL and Liao DF: Heat shock protein 90 acts as a molecular chaperone in late-phase activation of extracellular signal-regulated kinase 1/2 stimulated by oxidative stress in vascular smooth muscle cells. Acta Pharmacol Sin 28: 1907-1913, 2007.

25. Boucherat O, Peterlini T, Bourgeois A, Nadeau V, Breuils-Bonnet $S$, Boilet-Molez S, Potus F, Meloche J, Chabot S, Lambert C, et al: Mitochondrial HSP90 accumulation promotes vascular remodeling in pulmonary arterial hypertension. Am J Respir Crit Care Med 198: 90-103, 2018.

26. Wang GK, Li SH, Zhao ZM, Liu SX, Zhang GX, Yang F, Wang Y, Wu F, Zhao XX and Xu ZY: Inhibition of heat shock protein 90 improves pulmonary arteriole remodeling in pulmonary arterial hypertension. Oncotarget 7: 54263-54273, 2016

27. Li YP, Chen JJ, Shen JJ, Cui J, Wu LZ, Wang Z and Li ZR: Synthesis and biological evaluation of geldanamycin analogs against human cancer cells. Cancer Chemother Pharmacol 75: 773-782, 2015.

28. Supko JG, Hickman RL, Grever MR and Malspeis L: Preclinical pharmacologic evaluation of geldanamycin as an antitumor agent. Cancer Chemother Pharmacol 36: 305-315, 1995.

29. Egorin MJ, Lagattuta TF, Hamburger DR, Covey JM, White KD, Musser SM and Eiseman JL: Pharmacokinetics, tissue distribution, and metabolism of 17-(dimethylaminoethylamino)-17-demethoxygeldanamycin (NSC 707545) in CD2F1 mice and Fischer 344 rats. Cancer Chemother Pharmacol 49: 7-19, 2002. 